\title{
Stock Market Integration in Asian Countries: evidence from Wavelet multiple correlations
}

\author{
Aviral Kumar Tiwari \\ ICFAI University Tripura, Tripnra, India \\ Arif Billah Dar \\ Pondicherry University, Pnducherry, India \\ Niyati Bhanja \\ Pondicherry University, Pnducherry, India \\ Aasif Shah \\ Pondicherry University, Pnducherry, India
}

\begin{abstract}
This study examines the integration of nine Asian stock markets using the new methodology of wavelet multiple correlation and multiple cross-correlation proposed by Fernandez (2012). This novel approach eliminates several limitations which are encountered when conventional pairwise wavelet correlation and cross-correlation are used to assess the comovement of a set of stock indices. Our results show that Asian stock markets are highly integrated at lower frequencies and comparatively less integrated at higher frequencies. From the perspective of international investors, the Asian stock markets therefore offer little potential gains from international portfolio diversification especially for monthly, quarterly, and bi-annual time horizon investors, whereas, higher potential gains are expected at intraweek, weekly, and fortnightly time horizons.
\end{abstract}

JEL Classifications: F36, G11, G15

Key words: Asian Countries, International Portfolio Diversification, Stock Market Integration, Wavelet Multiple Correlation

\footnotetext{
* Corresponding Author: Aviral Kumar Tiwari; Research scholar and Faculty of Applied Economics, Faculty of Management, ICFAI University Tripura, Kamalghat, Sadar, West Tripura, Pin-799210, India; Tel: +91 8974105653, E-mail: aviral.eco@gmail.com, aviral. kr.tiwari@gmail.com.

Co-Author: Arif Billah Dar; Department of Economics, Pondicherry University, R.V. Nagar Kalapet Puducherry-605014, India; Tel: +91 9043909235, E-mail: billaharif0@gmail.com;

Niyati Bhanja; Department of Economics, Pondicherry University, R.V. Nagar Kalapet Puducherry-605014, India; Tel: +91 7598567017, E-mail: niyati.eco@gmail.com;

Aasif Shah; Department of Commerce, Pondicherry University, R.V. Nagar Kalapet Puducherry-605014, India; Tel: +91 8122263418,E-mail: shah_aasifpu@rediffmail.com.
} 


\section{Introduction}

The study of stock market integration is crucial in finance given its consequences for asset allocation decisions and portfolio diversification. Highly integrated stock market indices imply low benefits of international diversification, whereas segmented stock markets enable portfolio managers to diversify and benefit from differences in markets. Ever since Grubel (1968), the first treatise on the benefits of international portfolio diversification, issues related to the comovement of stock market returns have received a great deal of attention in international finance. A plethora of research activity has emerged on the co-movement of international stock prices (Lin et al. (1994), Karolyi and Stulz (1996), Forbes and Rigobon (2002), Brooks and Del Negro (2004), and Yang. J et al. (2006)). Conventionally, the study of stock returns co-movement has been undertaken through analysis of the correlation coefficient (Brooks and Del Negro (2004)). Later on more sophisticated methods like rolling window correlation (Brooks and Del Negro (2004)), non-overlapping sample periods (King and Wadhwani (1990) and Lin et al. (1994)), and cointegration (Voronkova, S. (2004)) have also been put to use. In Asia, studies based on cointegration have investigated the extent to which stock markets in the region are integrated and, in turn, have some implications with regard to diversification opportunities in Asian stock markets (Chan, Gup, and Pan, 1992; Hung and Cheung, 1995; DeFusco, Geppert, and Tsetsekos, 1996; Masih and Masih, 2001). Other related studies like Chung and Liu(1994) Arshanapalli, Doukas, and Lang(1995) Cheung(1997) Janakiramanan and Lamba(1998) Dekker, Sen, and Young(2001) employ vector autoregression (VAR) techniques, including cointegration, Granger causality, impulse response analysis, and forecast error variance decomposition. In general, these studies offer mixed empirical evidence with respect to both long-run and short-run relationships. Models based on cointegration and error correction, however, are plagued with several issues. For example, these models have been designed to deal with just two time frames or frequencies. However, given the heterogeneous trading in stock markets, participants in stock markets operate at different frequencies. Viewed through the portfolio diversification context, this means short-term investors are interested in stock returns at higher frequencies, that is, short-term fluctuations, while medium-term investors at medium frequencies, and the long-term investors are interested in relationships at lower frequencies, that is, long-term fluctuations. Therefore it is worth assessing stock market comovement at more than two frequencies. Frequency domain analysis, however, fails to reveal time information. Considering this limitation, some studies employ the wavelet methodology to distinguish short term, medium term, and long term comovements in stock returns. Recent application of wavelet analysis either uses pairwise wavelet correlation or regression within the set of multiple stock indices while examining the return spill-over effects between stocks, for example, Lee (2004), Sharkasi et al. (2004), Fernandez (2005), Rua and Nones (2009), and Raghavan et al. (2010). 
More recent study by Fernandez (2012) on developed eurozone markets has raised some issues related to the pairwise calculation of multi-scale correlations. For example, conventional wavelet methods that use stock returns for $n$ countries to calculate correlation and crosscorrelation end up with $n(n-1) / 2$ wavelet correlation graphs and $J$ (order of wavelet transform) times as many correlation graphs. ${ }^{1}$ This becomes a cumbersome and confusing process for the analyst who finally ends up with conflicting results and a large set of graphs. Moreover, within the multivariate context, a pairwise correlation coefficient could be spurious due to possible relationships of one variable with other variables. Finally, pairwise correlation in a multi-scale context leads to magnification of type 1 error due to experiment-wise error rate (see Cohen. $\mathrm{J}$ et al. (2003)). For a given wavelet scale, at the 5 percent level of significance, doing pairwise wavelet correlation significance tests with nine unrelated series of stock returns, the number of stock returns we are analyzing in our study will inflate the chance of type 1 error to 1 - (1$\alpha)^{36}=0.84$. This enhances the chance of finding significant correlation to 84 percent at a given wavelet scale somewhere among 36 tests instead of a mere 5 percent.

Given the aforementioned disadvantages of conventional wavelet based correlation and cross-correlation methods, this study therefore uses the wavelet multiple correlation and multiple cross-correlations proposed by Fernandez (2012) to analyze the relationship of nine Asian stock markets. The proposed methodology could be more useful than the conventional wavelet methods in least in three respects viz:

(1) Overall correlations within the multivariate set of different time scales in stock markets can be viewed in just two plots of wavelet multiple correlation and wavelet multiple cross-correlation.

(2) This method provides protection against spurious correlation obtained from the pairwise correlations within the multivariate set of stock returns.

(3) Finally, the proposed method is useful in providing protection against type 1 errors.

Our results based on this methodology show that there are strong linkages among the Asian stock markets and this integration grows stronger with lower frequencies. Asian stock markets therefore offer greater diversification opportunities at higher than lower frequencies.

The remainder of the paper is organised as follows. Section II gives a brief profile of selected Asian stock markets. The methodology is discussed in section III. Section IV sets out data description and discussion of results and, finally, Section V draws conclusions and policy implications.

\footnotetext{
In this paper since we are using nine countries and level six decomposition to measure stock return correlations, using pairwise wavelet correlation and cross-correlation we would have ended up with 36 wavelet correlation graphs and 216 cross-correlation graphs.
} 


\section{Profile of Selected Asian Stock Markets}

This section provides a brief background to the evolution of Asian stock markets (specific to the countries under consideration) in the light of deregulation and liberalization. The liberalization of a stock market basically means the decision on the part of a government to allow foreigners to purchase shares in a country's domestic stock market. More specifically, it allows foreign investors to invest in the equity securities of the domestic market and confers the right to domestic investors to transact in equity securities in foreign countries. The process of stock market liberalization has been quite different for developing Asian economies compared to the stock markets of developed economies. While by the early 1970s about 80 percent of stock markets in mature markets were already liberalized (e.g. Canada, France, Germany, Italy, the United Kingdom, and the United States), the most of the Asian stock markets were liberalized only during the 1980s except for Hong Kong (Kaminsky and Schmukler 2003).

Table 1. Liberalization Dates: Selected Asian Financial Markets

\begin{tabular}{|l|l||l|l|}
\hline Country & Liberalization date & Country & Liberalization date \\
\hline Japan & Jan 85 & South Korea & Jan 91p/May 98 \\
\hline Malaysia & Jul 73/Jan 75p/84 & Taiwan & Jan 87p/Apr 98 \\
\hline Indonesia & Dec $88 \mathrm{p} /$ Aug 89 & China & -NA- \\
\hline Hong Kong & Pre-73 & India & Jan 91 \\
\hline Singapore & Jan $86^{*}$ & --- & --- \\
\hline
\end{tabular}

(Note) This table reports the date of stock market liberalization for the different stock markets considered in this study. Where there is no information about the month of liberalization, we use January (December) if the corresponding report indicates that liberalization was implemented at the beginning (end) of the year. Pre73 (Pre-73p) means that the sector was already fully (partially) liberalized at that time, with no significant measures taken at that date.

(Source) Kaminsky, G.L., Schmukler, S.L., Short-run Pain, Long-run Gain: The Effects of Financial Liberalization, NBER Working paper 9787, June 2003, Table 1

*(Source) Phuan, S.M., Lim, K.P., Ooi, A. Y., Financial Liberalization and Stock Markets Integration for Asean-5 Countries, International Business Research, Vol.2, No.1, 2009

In fact, it was only during the latter half of the 1980s and the early years of the 1990s, that most of the governments in emerging Asian markets gradually liberalized their stock markets (details presented in Table 1). Moreover, the history of modern China's stock market is relatively young. The establishment of modern China's securities market started in 1986 and the Shanghai Stock Exchange (SHSE) was opened on December 19 ${ }^{\text {th }}, 1990$ (Lean 2010). Nevertheless, the stock market of China remained semi-repressed until late the 1990s, which 
immunized the Chinese economy from the Asian Crisis of 1997 1998 (Lee 2002). With accession to the WTO, however, China has opened its stock markets to international investors.

\section{Methodology}

The calculation of wavelet correlation involves the construction of variances and covariances of $\left(x_{t}\right)$ and $\left(y_{t}\right)$ at different wavelet scales. Wavelet variance essentially refers to the substitution of variability over certain scales for the global measure of variability estimated by sample variance. The wavelet variance of stochastic process $X$ is estimated using the MODWT(Maximal Overlap Discrete Wavelet Transform) coefficients for scale $\tau_{j}=2^{j-1}$ through:

$$
\hat{\sigma}_{x}^{2}\left(\tau_{j}\right)=\frac{1}{\hat{N}_{j}} \sum_{k=L_{j}-1}^{N-1}\left(\hat{W}_{j, k}\right)^{2}
$$

Where $\hat{W}_{j, k}$, the MODWT wavelet coefficient of variable $X$, at scale is $\tau_{j} . \hat{N}_{j}=N=L_{j}+1$ is the number of coefficients unaffected by the boundary, and $L_{j}=\left(2^{j}-1\right)\left(L^{-1}\right)+1$ is the length of the scale $\tau_{j}$ wavelet filter.

The wavelet covariance decomposes the covariance between two stochastic processes on a scale-by-scale basis. The wavelet covariance at scale $\tau_{j}$ can be written as follows:

$$
\gamma_{X Y}\left(\tau_{J}\right)=\operatorname{cov}_{X Y}\left(\tau_{J}\right)=\frac{1}{\hat{N}_{j}} \sum_{k=L_{j}-1}^{N-1} \hat{W}_{j, k}^{x} \hat{W}_{j, k}^{y}
$$

Given the wavelet covariance for $\left(x_{t}, y_{t}\right)$ and wavelet variances for $\left(x_{t}\right)$ and $\left(y_{t}\right)$, the MODWT estimator of wavelet correlation can be expressed as follows:

$$
\hat{\rho}_{x y}\left(\tau_{j}\right)=\frac{\operatorname{Cov}_{x y}\left(\tau_{j}\right)}{\hat{\sigma}_{x}^{2}\left(\tau_{j}\right) \hat{\sigma}_{y}^{2}\left(\tau_{j}\right)}
$$

The wavelet cross-correlation decomposes the cross-correlation between two time series on a scale-by-scale basis. Thus it becomes possible to see how the association between two time series changes with changes in the time horizon. Genaçay et al. (2002) define the wavelet cross-correlation as:

$$
\hat{\rho}_{x, k}\left(\tau_{j}\right)=\frac{\gamma_{x, k}\left(\tau_{j}\right)}{\hat{\sigma}_{1}\left(\tau_{j}\right) \hat{\sigma}_{2}^{2}\left(\tau_{j}\right)}
$$


Where $\sigma_{x, k}^{2}\left(\tau_{j}\right), \sigma^{2}\left(\tau_{j}\right)$ are, respectively, the wavelet variances for $x_{1, t}$ and $x_{2, t}$ associated with scale $\tau_{j}$ and $\gamma_{x, k}\left(\tau_{j}\right)$, and the wavelet covariance between $x_{1, t}$ and $x_{2, t-k}$ associated with scale $\tau_{j}$. The usual cross-correlation is used to determine lead-lag relationships between two time series; the wavelet cross-correlation gives a lead-lag relationship on a scale basis.

However, owing to the several limitations of pairwise correlation and cross-correlation, wavelet multiple correlation and cross-correlation suggested by Fernandez (2012) have been found useful. A multivariate stochastic process $X_{t}=\left(x_{1 t}, x_{2 t}, \ldots, x_{n t}\right)$ is defined. If $W_{j t}=\left(w_{1 j t}\right.$, $\left.w_{2 j t}, \ldots, w_{n j t}\right)$ represents the respective scale $\lambda_{j}$, wavelet coefficients are obtained by applying MODWT to each $x_{i t}$ process. The wavelet multiple correlation $(\mathrm{WMC}) \varphi_{X}\left(\lambda_{j}\right)$, defined as one single set of multi-scale correlations, can be calculated from $X_{t}$ as follows. For each wavelet scale $\lambda_{j}$, the square root of the regression coefficient of determination is calculated in the linear combination of variables $w_{1 j t}, i=1, \ldots, n$, for which the coefficient of determination is a maximum. The coefficient of determination corresponding to the regression of variable $z_{i}$ on a set of regressors $\left(z_{k}, k \neq i\right)$, is obtained as $R^{2}=1-1 / \rho^{i i}$, where $\rho^{i i}$ is the $i$-th diagonal element of the inverse of correlation matrix $P$.

The $\mathrm{WMC} \varphi_{X}\left(\lambda_{j}\right)$ is calculated as:

$$
\varphi_{X}\left(\lambda_{j}\right)=\sqrt{1-\frac{1}{\max \operatorname{diag} P_{j}^{-1}}},
$$

Here $P_{j}$ refers to the $n \times n$ correlation matrix of $W_{j t}$, and the max diag $(\cdot)$ operator provides selection for the largest element in the diagonal of the argument. In the regression of a $z_{i}$ on the rest of variables in the system, the $R_{i}^{2}$ coefficient can be equal to the square of the correlation between the observed values of $z_{i}$ and the fitted values $\hat{z}_{i}$ obtained from such a regression.

The WMC $\varphi_{X}\left(\lambda_{j}\right)$ can also be defined as:

$$
\varphi_{X}\left(\lambda_{j}\right)=\operatorname{Corr}\left(w_{i j t}, \hat{w}_{i j t}\right)=\frac{\operatorname{Cov}\left(w_{i j t}, \hat{w}_{i j t}\right)}{\sqrt{\operatorname{Var}\left(w_{i j t}\right) \operatorname{Var}\left(\hat{w}_{i j t}\right)}},
$$

where the wavelet variances and covariance are given by:

$$
\begin{gathered}
\operatorname{Var}\left(w_{i j t}\right)=\bar{\delta}_{j}^{2}=\frac{1}{T_{j}} \sum_{t=: j-1}^{T-1} w_{i j t}^{2} \\
\operatorname{Var}\left(\widehat{w}_{i j t}\right)=\bar{\xi}_{j}^{2}=\frac{1}{T_{j}} \sum_{t=: j-1}^{T-1} \widehat{w}_{i j t}^{2} \\
\operatorname{Cov}\left(w_{i j t}, \widehat{w}_{i j t}\right)=\bar{\gamma}_{j}=\frac{1}{T_{j}} \sum_{t=L_{j}-1}^{T-1} w_{i j t} \widehat{w}_{i j t}
\end{gathered}
$$


Where $w_{i j}$ on the set of regressors $\left(w_{k j}, k \neq i\right)$ leads to the maximization of the coefficient of determination, $\widehat{w}_{i j}$ represents the corresponding fitted values. The number of wavelet coefficients affected by the boundary associated with a wavelet filter of length $L$ and scale $\lambda_{j}$ is given by $L_{j}=\left(2^{j}-1\right)(L-1)+1$, then we have $\widetilde{T}_{j}=T-L_{j}+1$, the number of coefficients unaffected by the boundary conditions.

Finally, allowing a lag $\tau$ between observed and fitted values of the variable selected as the criterion variable at each scale $\lambda_{j}$, we may also define the wavelet multiple cross-correlation (WMCC) as

$$
\varphi_{X, \tau}\left(\lambda_{j}\right)=\operatorname{Corr}\left(w_{i j t}, \hat{w}_{i j t+\tau}\right)=\frac{\operatorname{Cov}\left(w_{i j t}, \hat{w}_{i j t+\tau}\right)}{\sqrt{\operatorname{Var}\left(w_{i j t}\right) \operatorname{Var}\left(\hat{w}_{i j t+\tau}\right)}},
$$

For the construction of confidence intervals it is assumed that $X=\left(X_{1} \ldots . X_{T}\right)$ is a realization of the multivariate Gaussian stochastic process of Equation (1)

$$
\text { and } \widetilde{W}_{j}=\left(\widetilde{W}_{j 0} \ldots W_{j, T-1}\right)=\left\{\left(\widetilde{w}_{1 j 0} \ldots \widetilde{w}_{n j 0}\right), . .,\left(\widetilde{w}_{1 j, T / 2^{j}-1}\right)\right\}, j=1 \ldots J \text {, are vectors of }
$$
wavelet coefficients obtained by applying a MODWT of order $\mathrm{J}$ to each of the univariate time series $\left(x_{i 1} \ldots x_{i T}\right)$ for $i=1 \ldots n$.

If $\widetilde{\varphi}_{X}\left(\lambda_{j}\right)$ is the sample wavelet correlation obtained from (1) then

$$
\widetilde{Z}_{j} \stackrel{a}{\sim} F N\left(z_{j},\left(T / 2^{j}-3\right)^{-1}\right)
$$

where

$\widetilde{Z}_{j}=\arctan h\left(\widetilde{\varphi}_{X}\left(\lambda_{j}\right)\right.$ and $F N$ stands for folded normal distribution.

The confidence interval $(C I)$ for the sample wavelet correlation coefficient is given as:

$$
C I_{1-\alpha}\left(\varphi_{X}\left(\lambda_{j}\right)=\tanh \left[\widetilde{z}_{j} \pm \phi_{1-\alpha / 2}^{-1} / \overline{T / 2^{j}-3}\right]\right.
$$

\section{Data, Results, and Discussion}

In this section we use the wavelet multiple correlation and wavelet multiple crosscorrelation using daily data of the following nine Asian stock market indices: India (BSE 30), China (SSEC), Japan (NIKKEI 225), Malaysia (KLCI), Hong Kong (HSI), Singapore (STI), South Korea (KOSPI), Indonesia (JCI), and Taiwan (TWII). ${ }^{2}$ The empirical data which have been taken from the Thomson database used in the study are daily from January 4, 2005 to

\footnotetext{
${ }^{2}$ These include some important countries like Asian tigers (Hong Kong, South Korea, Singapore, and Taiwan), Asian giants (China and India), Emerging markets (Malaysia and Indonesia), and a developed Asian market (Japan).
} 
February 28, 2012.

Table 2. Descriptive statistics of Asian stock returns

\begin{tabular}{|l|l|l|l|l|l|l|l|l|l|}
\hline & India & China & Japan & Malaysia & Hong Kong & Singapore & Korea & Indonesia & Taiwan \\
\hline Mean & 0.0002 & 0.0002 & 0.0001 & 0.0001 & 0.0001 & 0.0001 & 0.0001 & 0.0002 & 0.0001 \\
\hline Median & 0.0003 & 0.0004 & 0.000 & 0.0002 & 0.0002 & 0.000 & 0.000 & 0.006 & 0.000 \\
\hline Maximum & 0.0694 & 0.0392 & 0.057 & 0.024 & 0.0611 & 0.083 & 0.049 & 0.046 & 0.068 \\
\hline Minimum & -0.834 & -0.0615 & -0.052 & -0.0433 & -0.0693 & -0.040 & -0.048 & -0.051 & -0.039 \\
\hline Std.Dev. & 0.008 & 0.00823 & 0.007 & 0.0029 & 0.008 & 0.006 & 0.006 & 0.006 & 0.006 \\
\hline Skewness & -0.592 & -0.5201 & -0.672 & -1.18 & 0.088 & 1.0501 & -0.685 & -0.675 & 0.209 \\
\hline Kurtosis & 15.74 & 7.31 & 14.02 & 19.13 & 15.30 & 26.99 & 10.02 & 10.93 & 14.23 \\
\hline $\begin{array}{l}\text { Jarque-Bera } \\
\text { Probability }\end{array}$ & $\begin{array}{l}11577.63 \\
0.00\end{array}$ & $\begin{array}{l}1393.13 \\
0.00\end{array}$ & $\begin{array}{l}8713.05 \\
0.00\end{array}$ & $\begin{array}{l}18784.53 \\
0.00\end{array}$ & $\begin{array}{l}10702.29 \\
0.00\end{array}$ & $\begin{array}{l}40971.81 \\
0.00\end{array}$ & $\begin{array}{l}3618.36 \\
0.00\end{array}$ & $\begin{array}{l}4580.29 \\
0.00\end{array}$ & $\begin{array}{l}8934.30 \\
0.00\end{array}$ \\
\hline
\end{tabular}

As for missing data due to different public holidays in Asian stock markets, some daily observations were deleted. After matching the daily observations among the nine markets there were 1695 observations.

All indices were then transformed into daily returns by taking the log difference. Selected descriptive statistics of daily returns for all the stock market indices are presented in Table 2. Sample means, standard deviations, maximums, minimums, skewness, kurtosis and the JarqueBera statistic are reported. India, China, Malaysia, South Korea, and Indonesia have negative skewness, indicating that large negative stock returns are more common than large positive returns. Kurtosis statistics shows that all return series are leptokurtic, with significantly fatter tails and higher peaks. The Jarque-Bera statistics for all the indices strongly reject the null hypothesis that their distributions are normal.

Table 3. Time interpretation of different frequencies

\begin{tabular}{|c|c|c|}
\hline$w_{i 1}$ & $2 \sim 4$ days & Intraweek scale \\
\hline$w_{i 2}$ & $4 \sim 8$ days & Weekly scale \\
\hline$w_{i 3}$ & $8 \sim 16$ days & Fortnightly scale \\
\hline$w_{4 i}$ & $16 \sim 32$ days & Monthly scale \\
\hline$w_{5 i}$ & $32 \sim 64$ days & Monthly to quarterly scales \\
\hline$w_{6 i}$ & $64 \sim 128$ days & Quarterly to biannual scale \\
\hline
\end{tabular}

In order to calculate the wavelet multiple correlation we begin by decomposing the time 
series of stock returns into different time scales using Maximal Overlap Discrete Wavelet Transform (MODWT). We choose MODWT over the more conventional orthogonal DWT because, by giving up orthogonality, MODWT gains attributes that are far more desirable in economic applications. For example, MODWT can handle input data of any length, not just powers of two; it is translation invariant - that is, a shift in the time series results in an equivalent shift in the transform; it also has increased resolution at lower scales since it oversamples data (meaning that more information is captured at each scale); the choice of a particular wavelet filter is not so crucial if MODWT is used and, finally, except the last few coefficients, MODWT is not affected by the arrival of new information. Decomposition is carried out by using MODWT with Daubechies least asymmetric (LA) wavelet filter of length 8. Given the sample of 1695 observations and maximum decomposition possibility of $\left[\log _{2}(T)\right]$, we could have decomposed all the stock return series into ten details and one smooth component. However, for higher level decompositions, feasible wavelet coefficients get smaller, so we choose to decompose the time series of stock returns into six details $\left(w_{i 1}, \ldots w_{i 6}\right)$ and one $v_{i 6}$ smooth component. The corresponding time dynamics of each wavelet coefficient is given in Table 3 .

The wavelet multiple contemporaneous correlation with upper and lower bounds of 95 percent confidence intervals obtained from all the stock returns are shown in column 9 (lag zero) of Table 4 and its plots are shown in Figure 1 in the appendix. It can be seen that multiple correlations are high at all of the time scales. ${ }^{3}$ In particular correlation at the highest frequency (Intraweek) is 0.81 , for weekly 0.85 , for fortnightly, and for monthly 0.89 and this correlation grows stronger at lower frequencies and reaches 0.95 at the lowest frequency. This implies that Asian stock markets are nearly perfectly integrated in the long run (monthly, quarterly, and biannual scales), since the returns obtained in any of the Asian stock markets can almost always be explained by the overall performance in other Asian markets. The discrepancies between Asian stock markets are small and mostly fade within three to six months. We present the wavelet multiple cross-correlations for the different wavelet scales with leads and lags up to one month in Table 4 and Figure 2 in the appendix. The country that maximises the multiple correlation against the linear combination of other countries is shown in the upper right corner of Figure 2. As evident form Tables 4 and Figure 2 in the appendix, we find that multiple cross-correlation gets stronger with lower frequencies but gets weaker with successive lags. Interestingly, at the higher frequencies $w_{i 1}, w_{i 2}$ and $w_{i 3}$, Hong Kong maximises the multiple correlation against the linear combination of the other countries, whereas at other lower frequencies Singapore maximises the multiple correlation against the linear combination of the other countries. This indicates that Hong Kong has potential to lead or lag the other markets at higher frequencies $\left(w_{i 1}, w_{i 2}\right.$ and $\left.w_{i 3}\right)$ but at lower frequencies Singapore has the potential to lead

\footnotetext{
3 Results however should be interpreted with caution. Confidence intervals are based on fisher's result for usual bivariate correlation. We rely on simulation exercises carried in Javier Fernandez (2012), which show that this could be applicable for multivariate correlation also.
} 
or lag the other markets. Nevertheless, given the symmetry (zero skewness) in Figure 2, there is no clear evidence of a lead-lag potential of these two countries. We also find that multiple cross-correlations get stronger with lower frequencies.

Next, we test the robustness of the results using Daubechies least asymmetric (LA) wavelet filter of length 4, presented in Table 5. The results drawn using this filter confirm the earlier findings based on the $L A 8$ filter. Overall, we find strong linkages in the Asian stock market returns, especially at lower frequencies. In essence, our results are similar to the results of Fernandez (2012). From the perspective of international investors, the Asian stock markets, like European stock markets, offer little potential gains from international portfolio diversification especially for monthly, quarterly, and six monthly time horizon investors, whereas they offer relatively higher potential gains at intraweek, weekly and fortnightly time horizons.

\section{Conclusion and Policy Implications}

The study applied a new methodology based on wavelet multiple correlation and wavelet multiple cross-correlation to assess spillovers in the nine Asian stock markets. Wavelet multiple correlation was calculated as the square root of the regression coefficient of determination in that linear combination of wavelet coefficients for which the coefficient of determination is maximum. Our results, based on wavelet multiple correlation indicated that Asian stock markets are highly integrated at all studied frequencies. Moreover, this integration grows stronger with lower frequencies. Next, in order to calculate wavelet multiple cross-correlation, we allowed thirty lags between the observed and fitted values from the same linear combination, as before, at each of the wavelet scales. It was found that Hong Kong (at higher frequencies) and Singapore (at lower frequencies) were correlated against the linear combination of other stock returns at all lags and frequencies. However, multiple cross-correlation showed that crosscorrelation increases with lower frequencies but decreases with lags at all frequencies. These results for Asian stock markets are the unique contribution of this study. We would have ended up with erroneous and spurious thirty six wavelet correlation graphs and 216 wavelet crosscorrelation graphs using conventional pair wise correlations. In a nutshell, our results showed that there are more potential gains of diversification at lower frequencies (longer time horizons) than higher frequencies (shorter time horizons) in Asian stock markets. More specifically, the Asian stock markets provide more portfolio diversification opportunities for the short term investors compared to their long term counterparts.

Received 18 January, Revised 12 March 2013, Accepted 12 June 2013 


\section{References}

Arshanapalli, B., Doukas, J. and Lang, L.,(1995) "Pre and post-October 1987 stock market linkages between U.S. and Asian markets," Pacific-Basin Finance Journal 3, 57-73.

Brooks, R., Del Negro, M., (2004) "The rise in comovement across national stock markets: market integration or IT bubble?," Journal of Empirical Finance 11, 659-680.

Candelon, B., Piplack, J., Straetmans, S.,(2008) “On measuring synchronization of bulls and bears: the case of East Asia,” Journal of Banking and Finance 32, 1022-1035.

Chan, K.C., Gup, B.E. and Pan, M.,(1992) "An empirical analysis of stock prices in major Asian markets and the United States," Financial Review, 27, 289-307.

Cheung, D.,(1997) "Pacific Rim stock market integration under different federal funds rate regimes," Journal of Business Finance and Accounting, 24, 1343-1351.

Chung, P. and Liu, D.,(1994) “Common stochastic trends in Pacific Rim stock markets," Quarterly Review of Economics and Finance, 34, 241-259.

Cohen. J, Cohen. P, West. S, Aitken. L.,(2003) “Applied Multiple Regression and Correlation Analysis,” third ed., 1, Lawrence Erlbaum Associates, Inc., New Jersey.

DeFusco, R.A., Geppert, J. M. and Tsetsekos, G. P. (1996) "Long-run diversification potential in emerging stock markets," Financial Review, 31, 343-363.

Dekker, A., Sen, K. and Young, M.,(2001) "Equity market in the Asia Pacific region: A comparison of the orthogonalized and generalized VAR approaches," Global Finance Journal, 12, 1-33.

Fernandez, M. J.(2012) "Wavelet multiple correlation and cross-correlation: A multi-scale analysis of Eurozone stock markets.” phycica A 391 1097-1104.

Fernandez, V.,(2005) "Decomposition of Stock Returns Spillovers and Detection of Breakpoints in Volatility,"Centre for Applied Economics, Department of Industrial Engineering, University of Chile, Santiago.

Forbes, K., Rigobon, R.,(2002) "No contagion, only interdependence: measuring stock market comovements," Journal of Finance 57, 2223-2261.

Graham. M, Kiviaho. J, Nikkinen. J.,(2011) "Integration of 22 emerging stock markets: a three dimensional analysis," Global Finance Journal 16, 632-639.

Grubel, H.,(1968) "Internationally diversified portfolios: welfare gains and capital flows," American Economic Review 58 (5), 1299-1314.

Hung, B. and Cheung, Y.,(1995) "Interdependence of Asian emerging equity markets," Journal of Business Finance and Accounting, 22, 281-288.

Janakiramanan, S. and Lamba, A.S.,(1998) "An empirical examination of linkages between Pacific-Basin stock markets,” Journal of International Financial Markets, Institutions and Money, 8, 155-173.

Kaminsky, G.L., S.L. Schmukler,(2003) "Short-Run Pain, Long-Run Gain: The Effects of Financial Liberalization”, NBER Working Paper 9787, June.

Karolyi, G.A., Stulz, R.M., (1996) "Why do markets move together? Investigations of U.S.-Japan stock return comovements," Journal of Finance 51, 951-986. 
King, M., Wadhwani, S.,(1990) "Transmission of volatility between stock markets," Review of Financial Studies 3 (1), 5-33.

Lean, H. H., "Liberalization and Interaction among China's Stock Markets: A Re-visit, International of Chinese studies," Vol. 1, No. 3, December 2010, pp. 735-748.

Lee, H.S.,(2004) "International transmission of stock market movements: A wavelet analysis," Applied Economics Letters, Vol. 11 No. 3, pp. 197-201.

Lin,W. L., Engle, R., Ito, T.,(1994) "Do bulls and bears move across borders? International transmission of stock returns and volatility," Review of Financial Studies 7 (3), 507-538.

Mala Raghavan, Jonathan Dark, Elizabeth Ann Maharaj.,(2010) "International Journal of Managerial Finance," Vol. 6 No. 2, 116-127.

Masih, R. and Masih, A. M. M.,(2001) "Long and short term dynamic causal transmission amongst international stock markets," Journal of International Money and Finance, 20, 563-587.

Phuan, S.M., Lim, K.P., Ooi, A. Y.,(2009) “Financial Liberalization and Stock Markets Integration for Asean-5 Countries", International Business Research Vol.2, No.1.

Raghavan. M et. al., (2010) "Impact of capital control measures on the Malaysian stock market: A multiresolution analysis," International Journal of Managerial Finance, Vol. 6 Iss: 2, 116 - 127

Rua, António., Nunes Luis.,(2009) "International comovement of stock market returns: A wavelet analysis," Journal of Empirical Finance 16, 632-639

Sharkasi, A., Ruskin, H. and Crane, M.,(2004) "Interdependence between emerging and major markets," COMPSTAT Section: Application.

Voronkova, S.,(2004) "Equity market integration in Central European stock markets: A cointegration analysis with shifting regimes," International Review of Financial Analyst, 13, 633-647.

Yang,J., Hsiao, C., Li, Q.,\& Wang, Z.,(2006) “The emerging market crisis and stock market linkages: Further evidence,” Journal of Applied Econometrics 21, 727-744. 


\section{Appendices}

Figure1. Wavelet multiple correlations for Asian equity markets

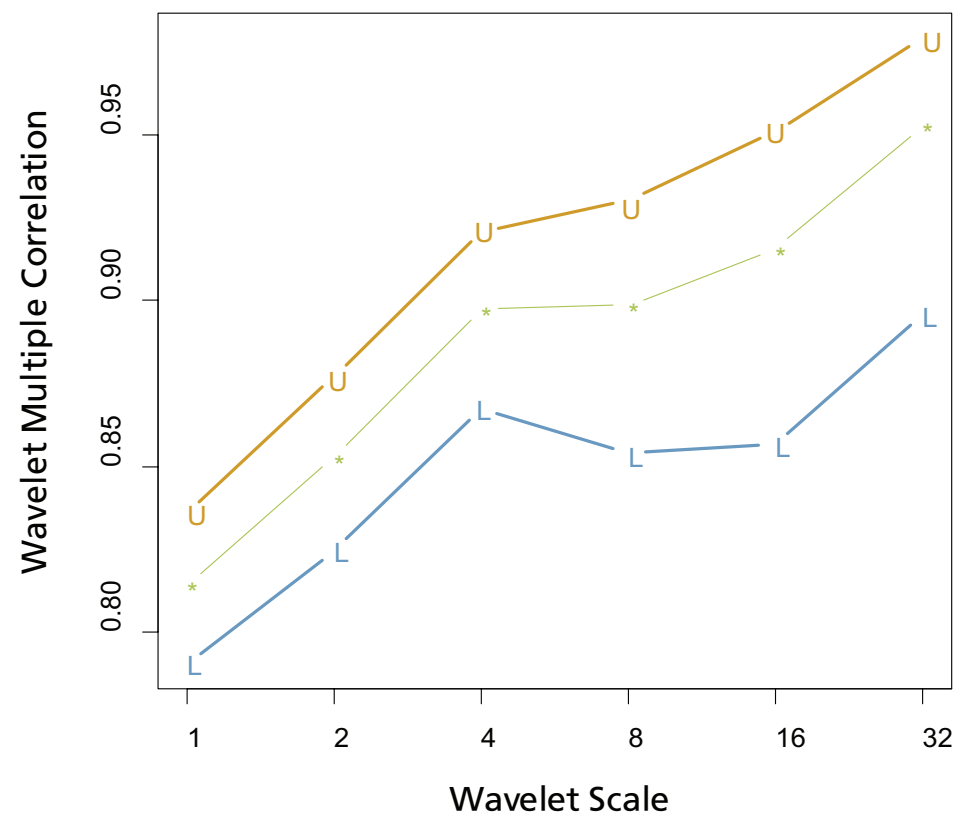

(Note) at different time scales using Daubechies least asymmetric (LA) wavelet filter of length 8. U and L indicate the upper and lower bounds of the $95 \%$ confidence interval. 
Figure 2. Wavelet multiple cross-correlations for Asian equity markets
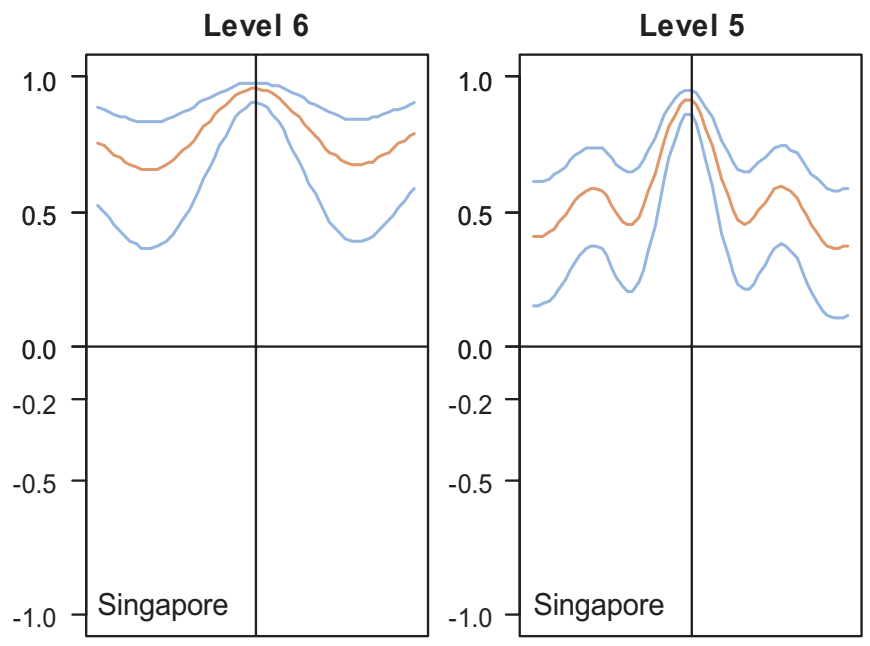

Level 3

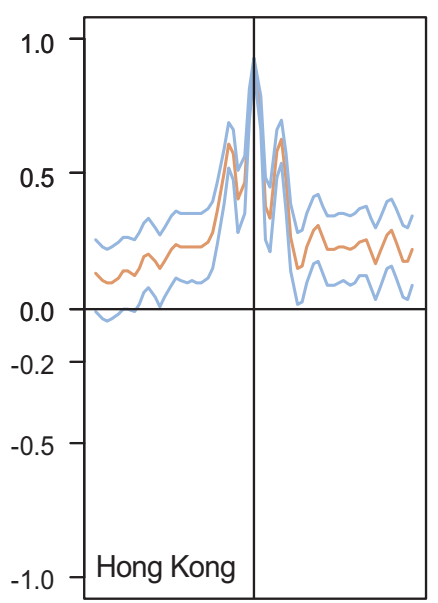

Level 2

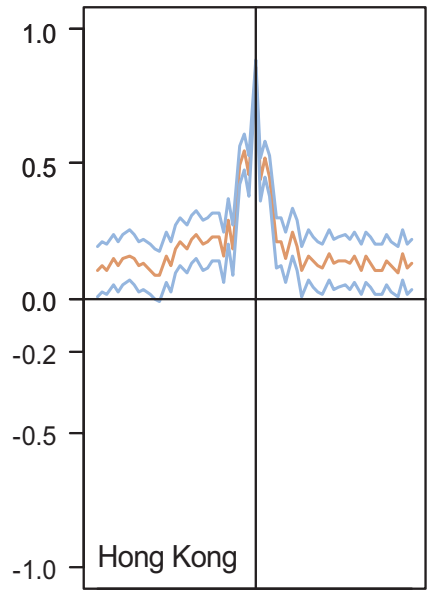

Level 4

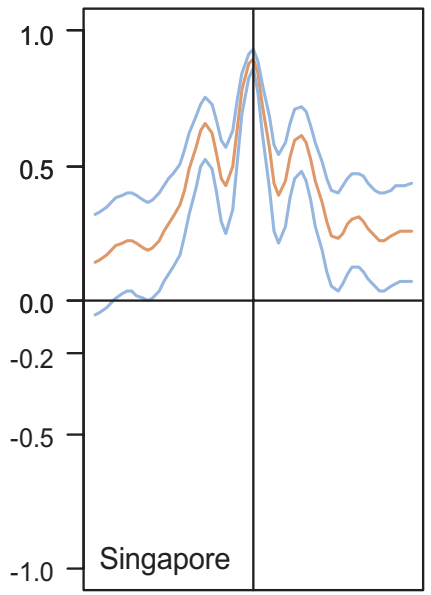

Level 1

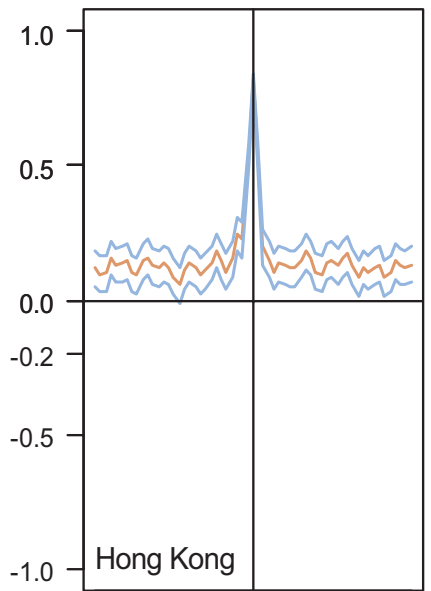

(Note) at different time scales using Daubechies least asymmetric (LA) wavelet filter of length 8, with Hong Kong acting as potential leader/follower at scales D1, D2, and D3 and Singapore acting as potential leader/ follower at scales D2, D3, and D4. The upper and lower bounds of the 95\% confidence interval. 
Table 4: Wavelet multiple correlation among Asian stock returns at different leads and lags using Daubechies least asymmetric (LA) wavelet filter of length 8.

\begin{tabular}{|c|c|c|c|c|c|c|c|c|c|c|c|c|c|c|c|}
\hline Lags $\rightarrow$ & & -10 & & & -5 & & & 0 & & & +5 & & & +10 & \\
\hline Scales $\downarrow$ & $L$ & Cor & $U$ & $L$ & Cor & $U$ & $L$ & Cor & $U$ & $L$ & Cor & $U$ & $L$ & Cor & $U$ \\
\hline$w_{i 1}$ & 0.02 & 0.09 & 0.16 & 0.04 & 0.10 & 0.17 & 0.79 & 0.81 & 0.83 & 0.06 & 0.12 & 0.19 & 0.09 & 0.17 & 0.22 \\
\hline$w_{i 2}$ & 0.06 & 0.19 & 0.25 & 0.16 & 0.28 & 0.34 & 0.82 & 0.85 & 0.87 & 0.08 & 0.19 & 0.27 & 0.01 & 0.15 & 0.20 \\
\hline$w_{i 3}$ & 0.03 & 0.22 & 0.29 & 0.40 & 0.60 & 0.60 & 0.86 & 0.89 & 0.91 & 0.42 & 0.62 & 0.62 & 0.05 & 0.22 & 0.31 \\
\hline$w_{4 i}$ & 0.37 & 0.62 & 0.65 & 0.20 & 0.42 & 0.53 & 0.84 & 0.89 & 0.92 & 0.17 & 0.38 & 0.51 & 0.31 & 0.57 & 0.61 \\
\hline$w_{5 i}$ & 0.11 & 0.47 & 0.58 & 0.47 & 0.76 & 0.79 & 0.84 & 0.91 & 0.94 & 0.41 & 0.68 & 0.76 & 0.13 & 0.45 & 0.59 \\
\hline \multirow[t]{2}{*}{$w_{6 i}$} & 0.45 & 0.80 & 0.86 & 0.72 & 0.91 & 0.94 & 0.89 & 0.95 & 0.97 & 0.68 & 0.89 & 0.93 & 0.41 & 0.77 & 0.84 \\
\hline & & -20 & & & -15 & & & 0 & & & +15 & & & +20 & \\
\hline$w_{i 1}$ & 0.08 & 0.15 & 0.22 & 0.01 & 0.08 & 0.15 & 0.79 & 0.81 & 0.83 & 0.08 & 0.15 & 0.21 & 0.01 & 0.08 & 0.14 \\
\hline$w_{i 2}$ & -0.00 & 0.10 & 0.18 & 0.06 & 0.17 & 0.25 & 0.82 & 0.85 & 0.87 & 0.02 & 0.13 & 0.21 & 0.00 & 0.10 & 0.18 \\
\hline$w_{i 3}$ & 0.03 & 0.20 & 0.29 & 0.07 & 0.23 & 0.33 & 0.86 & 0.89 & 0.91 & 0.05 & 0.22 & 0.31 & 0.07 & 0.25 & 0.33 \\
\hline$w_{4 i}$ & -0.07 & 0.18 & 0.30 & 0.05 & 0.30 & 0.41 & 0.84 & 0.89 & 0.92 & 0.00 & 0.23 & 0.37 & 0.07 & 0.30 & 0.42 \\
\hline$w_{5 i}$ & 0.18 & 0.57 & 0.63 & 0.21 & 0.52 & 0.65 & 0.84 & 0.91 & 0.94 & 0.24 & 0.55 & 0.67 & 0.20 & 0.54 & 0.64 \\
\hline \multirow[t]{2}{*}{$w_{6 i}$} & 0.14 & 0.62 & 0.74 & 0.24 & 0.69 & 0.78 & 0.89 & 0.95 & 0.97 & 0.20 & 0.65 & 0.77 & 0.12 & 0.62 & 0.73 \\
\hline & & -30 & & & -25 & & & 0 & & & +25 & & & +30 & \\
\hline$w_{i 1}$ & 0.04 & 0.11 & 0.18 & 0.06 & 0.13 & 0.19 & 0.79 & 0.81 & 0.83 & 0.01 & 0.08 & 0.14 & 0.06 & 0.13 & 0.19 \\
\hline$w_{i 2}$ & -0.01 & 0.09 & 0.17 & 0.03 & 0.14 & 0.22 & 0.82 & 0.85 & 0.87 & 0.04 & 0.14 & 0.22 & 0.02 & 0.12 & 0.21 \\
\hline$w_{i 3}$ & -0.03 & 0.11 & 0.23 & -0.02 & 0.12 & 0.24 & 0.86 & 0.89 & 0.91 & 0.11 & 0.27 & 0.36 & 0.06 & 0.21 & 0.32 \\
\hline$w_{4 i}$ & -0.07 & 0.13 & 0.30 & -0.02 & 0.21 & 0.34 & 0.84 & 0.89 & 0.92 & -0.00 & 0.21 & 0.36 & 0.03 & 0.25 & 0.39 \\
\hline$w_{5 i}$ & 0.04 & 0.40 & 0.53 & 0.04 & 0.45 & 0.54 & 0.84 & 0.91 & 0.94 & 0.03 & 0.38 & 0.53 & 0.02 & 0.37 & 0.52 \\
\hline$w_{6 i}$ & 0.34 & 0.72 & 0.80 & 0.18 & 0.64 & 0.76 & 0.89 & 0.95 & 0.97 & 0.22 & 0.68 & 0.77 & 0.42 & 0.77 & 0.85 \\
\hline
\end{tabular}

(Note) $\mathbf{C o r}=$ Correlation Coefficient., $\mathbf{L}=$ Lower bound of $95 \%$ confidence Interval., $\mathbf{U}=$ Upper bound of $95 \%$ confidence Interval. 
Table 5: Wavelet multiple among between Asian stock returns at different leads and lags using Daubechies least asymmetric (LA) wavelet filter of length 4.

\begin{tabular}{|c|c|c|c|c|c|c|c|c|c|c|c|c|c|c|c|}
\hline Lags $\rightarrow$ & & -10 & & & -5 & & & $\mathbf{0}$ & & & +5 & & & +10 & \\
\hline Scales $\downarrow$ & $L$ & Cor & $U$ & $L$ & $\mathrm{Cor}$ & $U$ & $L$ & Cor & $U$ & $L$ & Cor & $U$ & $L$ & Cor & $U$ \\
\hline$w_{i 1}$ & 0.03 & 0.10 & 0.16 & 0.04 & 0.11 & 0.18 & 0.79 & 0.82 & 0.84 & 0.07 & 0.13 & 0.20 & 0.10 & 0.17 & 0.23 \\
\hline$w_{i 2}$ & 0.07 & 0.16 & 0.25 & 0.17 & 0.26 & 0.34 & 0.82 & 0.85 & 0.87 & 0.09 & 0.18 & 0.27 & 0.02 & 0.11 & 0.21 \\
\hline$w_{i 3}$ & 0.03 & 0.16 & 0.29 & 0.41 & 0.51 & 0.61 & 0.86 & 0.89 & 0.92 & 0.43 & 0.53 & 0.62 & 0.06 & 0.19 & 0.32 \\
\hline$w_{4 i}$ & 0.37 & 0.53 & 0.65 & 0.20 & 0.38 & 0.53 & 0.85 & 0.89 & 0.93 & 0.18 & 0.36 & 0.51 & 0.31 & 0.48 & 0.61 \\
\hline$w_{5 i}$ & 0.12 & 0.38 & 0.59 & 0.48 & 0.66 & 0.79 & 0.85 & 0.91 & 0.95 & 0.42 & 0.62 & 0.76 & 0.13 & 0.39 & 0.60 \\
\hline \multirow[t]{2}{*}{$w_{6 i}$} & 0.46 & 0.72 & 0.86 & 0.73 & 0.87 & 0.94 & 0.89 & 0.95 & 0.98 & 0.69 & 0.85 & 0.93 & 0.41 & 0.69 & 0.85 \\
\hline & & -20 & & & -15 & & & 0 & & & +15 & & & +20 & \\
\hline$w_{i 1}$ & 0.09 & 0.15 & 0.22 & 0.03 & 0.085 & 0.15 & 0.79 & 0.82 & 0.84 & 0.08 & 0.15 & 0.22 & 0.01 & 0.08 & 0.15 \\
\hline$w_{i 2}$ & -0.00 & 0.09 & 0.19 & 0.07 & 0.16 & 0.25 & 0.82 & 0.85 & 0.87 & 0.03 & 0.12 & 0.22 & 0.00 & 0.10 & 0.19 \\
\hline$w_{i 3}$ & 0.03 & 0.17 & 0.29 & 0.07 & 0.21 & 0.33 & 0.86 & 0.89 & 0.92 & 0.06 & 0.19 & 0.32 & 0.07 & 0.21 & 0.33 \\
\hline$w_{4 i}$ & -0.07 & 0.12 & 0.31 & 0.06 & 0.25 & 0.42 & 0.85 & 0.89 & 0.93 & 0.01 & 0.20 & 0.38 & 0.07 & 0.26 & 0.43 \\
\hline$w_{5 i}$ & 0.19 & 0.44 & 0.64 & 0.21 & 0.46 & 0.65 & 0.85 & 0.91 & 0.95 & 0.25 & 0.49 & 0.67 & 0.21 & 0.45 & 0.65 \\
\hline \multirow[t]{2}{*}{$w_{6 i}$} & 0.15 & 0.50 & 0.75 & 0.25 & 0.58 & 0.79 & 0.89 & 0.95 & 0.98 & 0.20 & 0.55 & 0.77 & 0.12 & 0.49 & 0.74 \\
\hline & & -30 & & & -25 & & & 0 & & & +25 & & & +30 & \\
\hline$w_{i 1}$ & 0.048 & 0.11 & 0.18 & 0.07 & 0.13 & 0.20 & 0.79 & 0.82 & 0.84 & 0.01 & 0.08 & 0.15 & 0.07 & 0.13 & 0.20 \\
\hline$w_{i 2}$ & -0.01 & 0.08 & 0.18 & 0.03 & 0.13 & 0.22 & 0.82 & 0.85 & 0.87 & 0.04 & 0.14 & 0.23 & 0.03 & 0.12 & 0.21 \\
\hline$w_{i 3}$ & -0.03 & 0.10 & 0.23 & -0.02 & 0.11 & 0.24 & 0.86 & 0.89 & 0.92 & 0.11 & 0.24 & 0.37 & 0.07 & 0.20 & 0.33 \\
\hline$w_{4 i}$ & -0.07 & 0.12 & 0.31 & -0.03 & 0.16 & 0.35 & 0.85 & 0.89 & 0.93 & -0.01 & 0.19 & 0.36 & 0.03 & 0.22 & 0.40 \\
\hline$w_{5 i}$ & 0.04 & 0.31 & 0.54 & 0.05 & 0.32 & 0.54 & 0.85 & 0.91 & 0.95 & 0.04 & 0.31 & 0.54 & 0.02 & 0.29 & 0.53 \\
\hline$w_{6 i}$ & 0.35 & 0.65 & 0.83 & 0.19 & 0.54 & 0.76 & 0.89 & 0.95 & 0.98 & 0.22 & 0.56 & 0.78 & 0.43 & 0.70 & 0.85 \\
\hline
\end{tabular}

(Note) $\mathbf{C o r}=$ Correlation Coefficient., $\mathbf{L}=$ Lower bound of $95 \%$ confidence Interval., $\mathbf{U}=$ Upper bound of $95 \%$ confidence Interval. 